\section{Response to 'WHO classification of FGM omission and failure to recognise some women's vulnerability to cosmetic vaginal surgery'}

Many thanks to Hermione Lovel for her letter ${ }^{1}$ commending my personal view article on the vulva. ${ }^{2}$ I welcome the discussion as a way to further explore and emphasise this important topic. I want to respond to the points raised by Dr Lovel in turn.

I agree wholeheartedly with Dr Lovel that using international terminology is helpful in describing female genital mutilation (FGM), which is why I used, and referenced, the World Health Organization's definition. I also included the classification system in a table within the article.

I am sorry that Dr Lovel does not feel that I gave sufficient emphasis on FGM being a form of child abuse. In my article I describe the procedure in some detail (restraining a child and removing the external genital organs with crude instruments and with no anaesthetic). I also state that it can lead to life-threatening and lifelong complications as well as the permanent removal of sexual function. Finally, I note that FGM is regarded as a form of child abuse and sexual violence, which is illegal in most countries.

Regarding the vulnerability of women who have cosmetic vaginal surgery, there are unfortunately few data looking at the characteristics of women who undergo this type of surgery as it largely performed in the private sector. Without this evidence the statement that these women are "very often highly vulnerable" seems likely based on anecdotal observations and not something that I can personally substantiate. However, I do mention in my article that due to the potentially misleading nature of its marketing, the "FGCS industry may be seen to be exploiting the anxieties of vulnerable women".

Dr Lovel uses the terms "vaginoplasty" and "cosmetic vaginal surgery" to discuss my article about the vulva. A key point of the article was to try to promote awareness of issues relating specifically to the vulva as a distinct organ, with different characteristics to the vagina. My concern remains that using the terms interchangeably, as the public and our profession is prone to do, is both anatomically incorrect and can be confusing.

\section{Lucy Cox}

Saxonbrook Medical, Crawley, UK; lucyjcox@ doctors.org.uk

Competing interests None declared.

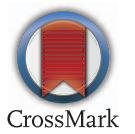

Received 10 February 2017

Accepted 13 February 2017

Published Online First 24 February 2017

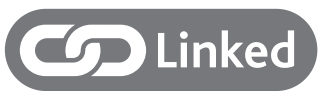

http://dx.doi.org/10.1136/jprhc-2016-101689

J Fam Plann Reprod Health Care 2017;43:166. doi:10.1136/jprhc-2017-101753

\section{REFERENCES}

1 Cox LJ. Ethics, aesthetics and euphemism: the vulva in contemporary society. J Fam Plann Reprod Health Care 2016;42:226-229.

2 Lovel H. WHO classification of FGM omission and failure to recognise some women's vulnerability to cosmetic vaginal surgery. J Fam Plann Reprod Health Care 2017;43:78. 